\title{
BMJ Open Factors associated with declining under-five mortality rates from 2000 to 2013: an ecological analysis of 46 African countries
}

\author{
Aaron M Kipp, ${ }^{1,2}$ Meridith Blevins, ${ }^{1,3}$ Connie A Haley, ${ }^{1,2}$ Kasonde Mwinga, ${ }^{4}$ \\ Phanuel Habimana, ${ }^{4}$ Bryan E Shepherd, ${ }^{1,3}$ Muktar H Aliyu, ${ }^{1,5}$ Tigest Ketsela, ${ }^{4}$ \\ Sten $\mathrm{H}$ Vermund ${ }^{1,6}$
}

To cite: Kipp AM, Blevins M, Haley CA, et al. Factors associated with declining under-five mortality rates from 2000 to 2013: an ecological analysis of 46 African countries. BMJ Open 2016;6:e007675. doi:10.1136/bmjopen-2015007675

\section{- Prepublication history} and additional material is available. To view please visit the journal (http://dx.doi.org/ 10.1136/bmjopen-2015007675).

Received 3 February 2015 Revised 17 August 2015 Accepted 21 September 2015

CrossMark

For numbered affiliations see end of article.

Correspondence to Dr Aaron M Kipp; aaron.kipp@vanderbilt.edu

\section{ABSTRACT}

Objective: Inadequate overall progress has been made towards the 4th Millennium Development Goal of reducing under-five mortality rates by two-thirds between 1990 and 2015. Progress has been variable across African countries. We examined health, economic and social factors potentially associated with reductions in under-five mortality (U5M) from 2000 to 2013.

Setting: Ecological analysis using publicly available data from the 46 nations within the WHO African Region.

Outcome measures: We assessed the annual rate of change (ARC) of 70 different factors and their association with the annual rate of reduction (ARR) of U5M rates using robust linear regression models.

Results: Most factors improved over the study period for most countries, with the largest increases seen for economic or technological development and external financing factors. The median (IQR) U5M ARR was $3.6 \%(2.8$ to $5.1 \%)$. Only 4 of 70 factors demonstrated a strong and significant association with U5M ARRs, adjusting for potential confounders. Higher ARRs were associated with more rapidly increasing coverage of seeking treatment for acute respiratory infection $(\beta=0.22$ (ie, a $1 \%$ increase in the ARC was associated with a $0.22 \%$ increase in ARR); $90 \% \mathrm{Cl} 0.09$ to 0.35 ; $\mathrm{p}=0.01$ ), increasing health expenditure relative to gross domestic product $(\beta=0.26 ; 95 \% \mathrm{Cl} 0.11$ to 0.41 ; $p=0.02)$, increasing fertility rate $(\beta=0.54 ; 95 \% \mathrm{Cl} 0.07$ to $1.02 ; \mathrm{p}=0.07)$ and decreasing maternal mortality ratio $(\beta=-0.47 ; 95 \% \mathrm{Cl}-0.69$ to $-0.24 ; \beta<0.01)$. The majority of factors showed no association or raised validity concerns due to missing data from a large number of countries.

Conclusions: Improvements in sociodemographic, maternal health and governance and financing factors were more likely associated with U5M ARR. These underscore the essential role of contextual factors facilitating child health interventions and services. Surveillance of these factors could help monitor which countries need additional support in reducing U5M.

\section{Strengths and limitations of this study}

- This study represents a comprehensive analysis of health factors and other determinants of health associated with declining under-five mortality in Africa.

- Study findings highlight the role of financing, economy and the broader health system in more rapidly reducing an already declining, albeit slowly, under-five mortality rate above and beyond the contribution of individual interventions.

- Inferences of causality may be limited due to the ecological study design and that the time periods for change in coverage of the factors did not always fully overlap with time periods for change in under-five mortality.

- The small sample size (at most $n=46$ countries, but often smaller due to missing data) limits the validity of some associations and prevents adjustment for too covariates.

\section{INTRODUCTION}

Under-five mortality (U5M) rates have declined worldwide from an estimated 90 deaths per 1000 live births in 1990 to 46 deaths per 1000 in 2013, representing an average annual rate of reduction (ARR) of 3\%. ${ }^{1}$ Higher income regions had an estimated U5M rate of 6 deaths per 1000 live births in 2012 (3.8\% ARR); they account for only $1.4 \%$ of all under-five deaths. In contrast, the WHO African Region (including 46 countries in 2012; figure 1 and table 1) experienced 90 under-five deaths per 1000 live births in 2013 and a 1990-2013 ARR of 2.9\%. Thus, African children are nearly 16 times more likely to die under age five than children from high income nations, though progress in Africa is being made.

In 2000, the 4th Millennium Development Goal (MDG4) ${ }^{2}$ proposed the reduction of the U5M rate by two-thirds between 1990 
and 2015, requiring a global average ARR of $4.4 \%$ to reach this goal. Africa has more than tripled its U5M ARR from $1.3 \%$ in $1990-2000$ to $4.2 \%$ in $2000-2013$, but the ARR achievements are inadequate to meet the MDG4 targets. ${ }^{1}$ Proven cost-effective child survival interventions and proposed delivery channels for those interventions need to be scaled up. ${ }^{3-7}$ The Countdown to 2015 for Maternal, Newborn and Child Survival initiative was created in 2005 to monitor the use of these evidencebased interventions for maternal, neonatal and child health. ${ }^{8}$ In 2012, the Countdown's 75 priority countries accounted for $>95 \%$ of all maternal and child deaths. ${ }^{9} 10$ Of note, $41(55 \%)$ of the 75 Countdown priority countries come from the 46 WHO African Region countries (the exceptions were Algeria, Cape Verde, Mauritius, Namibia and Seychelles).

In 2006, WHO, the United Nations Children's Fund, and the World Bank developed Child Survival Strategy for the African Region aimed to support countries' efforts to reduce child deaths from preventable and treatable conditions by scaling up coverage of effective interventions. ${ }^{6}$ These include antenatal care, postnatal care, infant and young child feeding, the expanded programme on immunisations, integrated management of common childhood illness, prevention of mother-to-child transmission of HIV and use of insecticide treated nets, among others. As of 2013, 38 of the 46 African countries had developed or updated national child survival policies, strategies and plans. Population coverage in the African Region has increased with time, leading to high coverage of measles vaccination, neonatal tetanus protection, antiretroviral drugs for prevention of mother-to-child transmission of HIV and at least one antenatal care visit for every pregnant woman. ${ }^{11}$ Coverage of other interventions remain low, however, in spite of recent increases in coverage, including exclusive breastfeeding, pneumococcus and Haemophilus influenzae vaccination, treatment of childhood diarrhoea, pneumonia and malaria, and use of insecticide treated nets. Despite progress, Africa is not on track to reach MDG4 due to inconsistent and suboptimal implementation and scale-up of evidence-based maternal, neonatal and child health interventions. ${ }^{10}$ With variable progress across countries in improving child survival in Africa, understanding factors associated with the most rapid changes in U5M reductions could assist regional and country efforts to improve child survival in the post-2015 era.

We sought to identify proximal (eg, interventions and services) and distal (eg, socioeconomic) factors influencing how rapidly countries reduce U5M, as evidenced by their ARR. An ecological analysis of country-level data was used to determine which factors previously reported to reduce U5M are also the factors most strongly associated with higher ARRs in Africa.

\section{METHODS}

The study was approved by the Institutional Review Boards at Vanderbilt University.
Mortality data were obtained for the period 20002013, while data on all factors of interest were obtained for the period 1998-2011. These are described in detail below.

\section{Under-five mortality data}

We obtained country-specific U5M rates from annual estimates provided by http://www.childmortality.org, the data used in the United Nations Children's Fund (UNICEF) Report on Levels and Trends in Child Mortality. For each of the 46 WHO African Region countries, the estimated U5M rates for 2000 and 2013 (the latest estimates available at the time of the analysis (accessed June 2015)) were obtained and the ARR from 2000 to 2013 was calculated. Use of the ARR as an outcome facilitates interpretation of results in the context of MDG4 progress metrics.

The U5M ARR reflects a constant rate of change in the U5M rate between two time periods and is calculated using the following equation (equation 1 ):

$$
\mathrm{ARR}=\left(\frac{\ln \left[\mathrm{y}_{\mathrm{t}+\mathrm{n}} / \mathrm{y}_{\mathrm{t}}\right]}{\mathrm{n}}\right) \times(-100)
$$

where $y_{t}$ is the mortality rate for a given year $(e g, 2000)$ and $\mathrm{n}$ is the number of years between the two rates (eg, 13 years when calculating ARR from 2000 and 2013 rates). Consistent with how it is calculated and reported by $\mathrm{UNICEF}^{1}$ and others, ${ }^{12}$ the ARR is expressed as a per cent and will have a positive value when a country is reducing its mortality rate. As an example, an ARR of $4.4 \%$ or greater is needed for a country to meet MDG4 of reducing U5M by two-thirds between 1990 and 2015 . In the years leading up to 2015, expressing the reduction in U5M as an ARR made it possible to monitor progress across countries and over different time periods.

\section{Factors potentially associated with child mortality Identification}

Since we wanted to assess a broad range of factors potentially associated with U5M ARR, factors to be used in the analysis included those monitored by Countdown to 2015 as well as others identified through a comprehensive literature search of the PubMed database. We searched for studies on under-five, infant or neonatal mortality within any of the 46 countries in the WHO African Region that were published between 2002 and 2012. Abstracts were reviewed to identify factors that were (1) associated with under-five, infant or neonatal mortality, (2) not already reported by Countdown to 2015 and (3) had aggregate country-level data available for the analysis. Thirty-four factors met these criteria. These were combined with 20 Countdown 2015 intervention indicators (or closely related) and 16 nonintervention indicators reported in the Countdown 2015 country profiles (or were closely related). The final list used in the analysis included 70 factors from the 
following categories: sociodemographics (18 factors), access to healthcare (16), governance and financing (11), maternal health (6), child survival interventions (7), clinical and health conditions (7), and other country infrastructure (5) (see online supplemental table S1).

\section{Data sources and inclusion criteria}

Data for $58(83 \%)$ of the 70 indicators were obtained from the World Bank Data Catalogue. ${ }^{13}$ The World Bank Data Catalogue is a repository of national, regional and global indicator data that have been compiled from officially recognised international sources. In many instances, a single indicator may be derived from multiple data sources using modelling or aggregation techniques. Data for the remaining 12 factors not available through the World Bank Data Catalogue were obtained directly from each country's Demographic and Health Surveys ${ }^{14}$ (10 factors) or Countdown 2015 country profiles (2 factors). ${ }^{8}{ }^{10}$ In total, $26(37 \%)$ of 70 factors were obtained entirely or in part from country Demographic and Health Surveys or other household survey data, including the majority of the maternal health, access to healthcare and child survival intervention factors. Other sources included data collected and maintained by WHO, various UN divisions, UNAIDS, the Organisation for Economic Co-operation and Development, and the World Bank (see online supplemental tables S2 and S3 for further details).

For each of the 46 WHO African Region countries, data on the 70 factors were obtained that corresponded as close as possible to the years 2000 and 2011. To be considered sufficient for inclusion in the analyses, data for each factor had to meet the following three criteria: (1) reported for one of the years between 1998 and 2003 , termed 2000 data, (2) reported for one of the years between 2006 and 2011, termed 2011 data and (3) the pair of data points for each factor had to be at least 5 years apart in order to minimise incorrect extrapolation when calculating changes in the indicator. If any of these criteria were not met, the change over time for that particular factor was not calculated and was deemed missing.

\section{Indicator annual rate of change calculation}

The annual rate of change (ARC) for each indicator is conceptually similar to the ARR for U5M and was calculated using the same ARR equation shown above in equation 1 but with one difference: the rate of change is multiplied by positive 100 instead of negative 100 so that the ARC has a negative value when the indicator decreases over time (ie, Coverage $2011<$ Coverage $_{2000}$ ) and a positive value when the indicator increases over time (equation 2):

$$
\mathrm{ARC}=\left(\frac{\ln \left[\mathrm{y}_{\mathrm{t}+\mathrm{n}} / \mathrm{y}_{\mathrm{t}}\right]}{\mathrm{n}}\right) \times
$$

This is in contrast to the U5M ARR which has a positive value when mortality is decreasing over time (ie, $\left.\mathrm{U} \mathrm{M}_{2013}<\mathrm{U}_{5} \mathrm{M}_{2000}\right)$.

\section{Statistical analysis}

The dependent variable of interest was the U5M ARR for 2000-2013. Each indicator ARC was an independent variable of interest. Both indicator ARCs and U5M ARR were analysed as continuous variables and no transformations were performed. The distribution of ARRs was inspected visually and was confirmed to be approximately normal by the Shapiro-Wilk test for normality $(\mathrm{p}=0.33)$. Associations were explored using linear regression. Given the sample size $(n=46$ countries), results from traditional linear regression methods may be overly influenced by outliers. These outliers, however, likely represent true data rather than data errors and exclusion would unnecessarily decrease the sample size. Hence, robust linear regression was used to minimise the influence of outlying observations, without excluding them ${ }^{15-17}$ using iteratively reweighted least squares (M-estimation with Huber weighting).

Multivariable robust linear regression models were fit for each factor of interest, resulting in 70 different regression models (one for each factor). A standard set of factors was identified a priori to be included in each model as covariates to adjust for potential confounding of the specific factor association being analysed. Given the sample size of 46 countries, at most, a decision was also made a priori to include no more than five covariates in the multivariable analyses to avoid overfitting. We selected the following factor ARCs for inclusion as covariates in each model based on previous ecological studies, consideration of what macro-level or system-level factors would influence the majority of the factors, and having nearly complete data: (1) access to improved water source, (2) health expenditure (relative to gross domestic product (GDP)), (3) adult HIV prevalence, (4) urban population prevalence and (5) receipt of antenatal care (when applicable). All regression models included these core factor ARCs as covariates unless expected to be highly correlated with the primary indicator of interest (eg, improved water sources was excluded from the model for the association between improved sanitation facilities; health expenditure relative to GDP was excluded from the model for the association between health expenditure relative to government expenditure). Changes in the receipt of antenatal care was only included when the indicator being analysed would occur following the pregnancy period (eg, maternal mortality ratio, births delivered at a health facility, measles immunisation, wasting prevalence) and was not included for sociodemographic factors, macro-level factors such as health expenditure and system-level factors such as physician density.

The estimated robust linear regression $\beta$ coefficient for each indicator ARC and U5M ARR association can be interpreted as the change in ARR associated with 
every $1 \%$ increase in the indicator ARC. For example, a $\beta$ coefficient of 0.20 indicates that for every $1 \%$ increase in the indicator ARC there is a corresponding $0.2 \%$ increase in the ARR. Stated differently, a $5 \%$ increase in the indicator ARC (eg, 6\% ARC compared to $1 \%$ ARC) corresponds to a $1 \%$ increase in the ARR (eg, $4 \%$ ARR vs $3 \%$ ARR). To help avoid type II errors, which can occur with small samples, we reported all associations when the $\mathrm{p}$ values were $<0.10$, acknowledging that some of these associations may be due to chance alone, especially with higher $p$ values. We report an indicator to be strongly associated with ARR when the adjusted $\beta$ coefficient is $\geq 0.20$ or $\leq-0.20$.

A preliminary analysis showed significantly different ARRs between countries reporting a specific indicator and countries not reporting a specific indicator when the indicator was reported by $<50 \%$ of the countries. Since these differences suggest selection bias, we only present results for those factors for which at least 23 countries $(\geq 50 \%)$ have sufficient data (ie, non-missing indicator data for both time periods). Results for all factors are available in online supplemental tables S4 and S5.

All analyses were conducted using R-software V.2.15.2 (http://www.r-project.org).

\section{RESULTS}

\section{Country-specific progress in U5M}

As of 2013, U5M rates and corresponding ARRs for each of the 46 WHO African countries vary widely, with a median (IQR) of $3.6 \%$ (2.8\% to $5.1 \%$; figure 1 ; table 1 ). Eleven countries (Eritrea, Ethiopia, Liberia, Madagascar, Malawi, Mozambique, Niger, Rwanda, Senegal, Tanzania and Uganda) have met or are on track to meet their MDG4 target. An additional four countries (Algeria, Cape Verde, Mauritius and Seychelles) are considered on track due to U5M rates $<40$ per 1000 . Eight countries were making very little progress with ARRs $\leq 2 \%$ : Angola, Central African Republic, Chad, Comoros, Ghana, Lesotho, Mauritania and Zimbabwe. Of the remaining 23 countries, some were making good progress but will fall just short of their MDG4 target (eg, Congo, Mali and Zambia), while others were making some progress but still have a considerable ways to go before reaching MDG4 (eg, Cameroon, Kenya and South Africa; table 1).

\section{Descriptive results of selected factors}

Of the 70 factors identified, $60(86 \%)$ had sufficient data from at least one country for the period 2000-2011. Of these, $41(68 \%)$ factors had data for at least $50 \%$ of the countries and are shown in table 2. The largest ARCs were generally observed for factors related to economic or technological development and external financing, ranging from an ARC of $4.2 \%$ (GDP per capita) to $29 \%$ (internet users) and including, for example, external resources for health (ARC of 6.2\%). An extremely large ARC also occurred for use of insecticide-treated bednets (ARC of 29.0\%), an intervention which can be rapidly scaled up and which also had the lowest coverage at the start of the study period (2\% in 2000). In contrast, vitamin A supplementation had very high coverage at the start of the study period $(91 \%)$ and did not change dramatically over time (ARC of $-0.3 \%$ ). Coverage of other child survival interventions or access to healthcare generally improved over the study period with ARCs from $1.2 \%$ to $4.0 \%$. Some countries, however, had worsening coverage over time as indicated by negative ARCs in the IQR. Adverse health conditions improved slowly over the study period with ARCs from $-0.3 \%$ to $-1.9 \%$, and the largest improvement was seen for maternal mortality ratio (ARC of $-3.7 \%$ ). Similar to the adverse health conditions, sociodemographic factors improved over the study period for nearly all countries, with ARCs ranging from $0.1 \%$ to $3.2 \%$. Details of all indicator ARCs are in online supplemental table S4.

\section{Associations between indicator ARCs and U5M ARRs}

There was evidence that ARRs were higher for countries that had more complete data reported for use in the analyses (figure 2). However, of the results presented below, all but one factor was reported by $>30$ countries.

Four indicator ARCs were strongly and statistically associated with U5M ARR after adjusting for potential confounders (table 3 , in bold). With three of these, larger ARCs were associated with larger U5M ARRs: fertility rate $(\beta=0.54 ; p=0.07)$, health expenditure relative to GDP $(\beta=0.26 ; p=0.01)$ and seeking treatment for acute respiratory infection (ARI) $(\beta=0.22 ; p=0.01)$. With the fourth, larger ARCs for maternal mortality ratio were inversely associated with unfavourable and larger decreases in U5M ARR $(\beta=-0.47 ; \mathrm{p}<0.01)$.

An additional four factors had large $(\beta \geq 0.20$ or $\beta \leq$ $-0.20)$ but statistically non-significant $(p \geq 0.10)$ associations with U5M ARR, while another four showed small but statistically significant associations $(\beta<0.20$ with $\mathrm{p}<0.10$; table 3 ). Of the remaining 58 factors considered in this analysis, 27 had sufficient data from at least 23 of the 46 countries, but there was no association with U5M ARR $(\beta<0.20$ and $p \geq 0.10$; seven are shown in table 3$)$. The final 31 factors had no data available for analysis $(n=10)$ or were reported by $<23$ countries and not presented here due to concerns about selection bias. Results for all 70 factors are available in online supplemental table S5.

\section{DISCUSSION}

Our study represents a comprehensive analysis of health-related factors and other determinants of health associated with declining U5M in Africa. From 70 factors considered, only four were found to have a strong and statistically significant association with higher rates of reduction in U5M between 2000 and 2013: more rapid increases in fertility rate, health expenditure relative to 


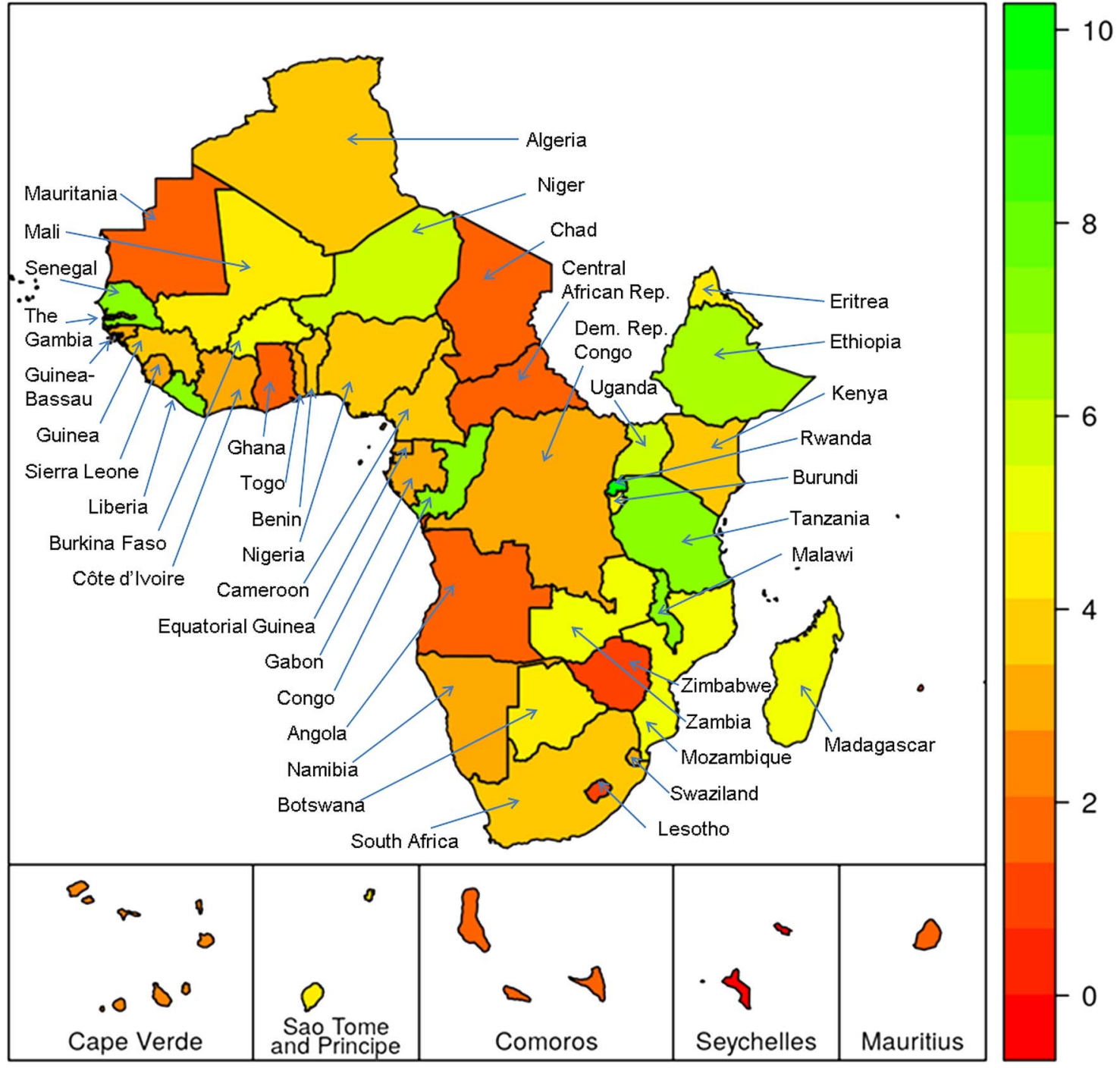

Figure 1 Annual rate of reduction (ARR) in under-five mortality for the 46 countries in the WHO African Region, 2000 to 2013 (Higher ARRs indicate more progress, represented by a greener colour on the map). The WHO African Region excludes Djibouti, Egypt, Libya, Morocco, Somalia, Sudan and Tunisia; all are included in the WHO Eastern Mediterranean Region. From May 2012, South Sudan is now officially part of the African Region but was not an independent WHO member nation during the study period.

GDP and seeking treatment for ARI, and a more rapid decrease in maternal mortality ratio. Maternal mortality ratio showed a particularly strong association $(\beta=-0.47)$, indicating that a $1 \%$ increase in the annual reduction of the maternal mortality ratio was associated with a $0.47 \%$ increase in the U5M ARR. The associations for health expenditure relative to GDP and seeking treatment for ARI were half this magnitude $(\beta=0.26$ to $\beta=0.22$, respectively.

The strong and statistically significant association between more rapid declines in the maternal mortality ratio and U5M ARR may well represent the direct negative effect of maternal death on subsequent child survival. It may also be indicative of health systems that do poorly in preventing both maternal and child deaths. More rapid increases in treatment-seeking behaviour for ARI was the only health-related access or intervention factor found to associate with a larger U5M ARR. Validation studies suggest that factors of access to care or behaviour (eg, seeking ARI treatment) may be more reliably measured than actual treatment (eg, children with ARI receiving treatment; we had insufficient data to analyse this), since quality of care and ability to recall symptoms may bias the coverage estimates. ${ }^{18} 19$ Similar concerns exist about reliability of vaccination coverage estimates due to information bias on the vaccination card or recall bias from maternal reports. ${ }^{20}$ This may explain, in part, why some of these factors were not associated with ARR in our study.

The association between fertility rate and higher U5M ARRs is at first counterintuitive. However, as shown in table 2, fertility rates are declining (negative ARC) in nearly all 46 of the countries. Thus, slower declines in fertility rates are associated with more rapid reductions 
Table 1 Under-five mortality rates and annual rate of reduction (ARR) for the 46 countries in the WHO African Region, 2000-2013

\begin{tabular}{|c|c|c|c|c|c|}
\hline \multirow[b]{2}{*}{ Country } & \multicolumn{3}{|c|}{$\begin{array}{l}\text { Under-five mortality rate (per 1000) } \\
\text { in the given year* }\end{array}$} & \multirow{2}{*}{$\begin{array}{l}\text { ARR (\%) } 2000 \\
\text { to } 2013\end{array}$} & \multirow{2}{*}{$\begin{array}{l}\text { ARR (\%) in } 2000-2015 \\
\text { needed to meet MDG }\end{array}$} \\
\hline & 2000 & 2013 & MDG for 2015 & & \\
\hline Angola & 216.7 & 167.4 & 75.3 & 2.0 & 7.0 \\
\hline Benin & 146 & 85.3 & 59.8 & 4.1 & 6.0 \\
\hline Botswana & 85.1 & 46.6 & 16.5 & 4.6 & 10.9 \\
\hline Cameroon & 151.2 & 94.5 & 45.5 & 3.6 & 8.0 \\
\hline Cape Verde† & 35.3 & 26 & 21.0 & 2.4 & 3.5 \\
\hline Central African Republic & 174.1 & 139.2 & 59.0 & 1.7 & 7.2 \\
\hline Chad & 190.7 & 147.5 & 71.6 & 2.0 & 6.5 \\
\hline Comoros & 101.3 & 77.9 & 41.8 & 2.0 & 5.9 \\
\hline Eritrea & 89.3 & 49.9 & 50.2 & 4.5 & 3.8 \\
\hline Ethiopia & 145.5 & 64.4 & 68.3 & 6.3 & 5.0 \\
\hline Gabon & 84.6 & 56.1 & 30.9 & 3.2 & 6.7 \\
\hline Gambia & 119 & 73.8 & 56.6 & 3.7 & 5.0 \\
\hline Ghana & 101.3 & 78.4 & 42.7 & 2.0 & 5.8 \\
\hline Guinea & 170.2 & 100.7 & 79.2 & 4.0 & 5.1 \\
\hline Guinea-Bissau & 180.8 & 123.9 & 74.9 & 2.9 & 5.9 \\
\hline Kenya & 110.9 & 70.7 & 32.9 & 3.5 & 8.1 \\
\hline Lesotho & 114.6 & 98 & 28.8 & 1.2 & 9.2 \\
\hline Liberia & 175.2 & 71.1 & 82.7 & 6.9 & 5.0 \\
\hline Madagascar & 110.6 & 56 & 53.6 & 5.2 & 4.8 \\
\hline Rwanda & 181.9 & 52 & 50.6 & 9.6 & 8.5 \\
\hline Sao Tome and Principe & 89.3 & 51 & 36.8 & 4.3 & 5.9 \\
\hline Senegal & 137 & 55.3 & 47.0 & 7.0 & 7.1 \\
\hline Seychellest & 14.2 & 14.2 & 5.5 & 0.0 & 6.3 \\
\hline Sierra Leone & 231.5 & 160.6 & 89.2 & 2.8 & 6.4 \\
\hline South Africa & 74.3 & 43.9 & 20.3 & 4.0 & 8.6 \\
\hline Swaziland & 122.5 & 80 & 24.6 & 3.3 & 10.7 \\
\hline Togo & 121.8 & 84.7 & 48.8 & 2.8 & 6.1 \\
\hline Uganda & 147 & 66.1 & 59.6 & 6.1 & 6.0 \\
\hline United Rep. of Tanzania & 131.5 & 51.8 & 55.7 & 7.2 & 5.7 \\
\hline Zambia & 168.8 & 87.4 & 64.2 & 5.1 & 6.4 \\
\hline Zimbabwe & 102.6 & 88.5 & 24.9 & 1.1 & 9.4 \\
\hline
\end{tabular}

in U5M-something that becomes more intuitive in the context of demographic transition, Birth rates begin to decline typically only after mortality rates have begun to decline. The observed association may therefore reflect that much of Africa is in the early and middle stages of the demographic transition. Countries with the most rapid reductions in U5M have just begun to reduce their fertility rates, while countries that previously had substantial reductions in mortality (and therefore smaller ARRs in the recent past) have the most rapid reductions 
Table 2 Median 2000 indicator values and corresponding indicator annual rate of change (ARC) for the 2000-2011 period

\begin{tabular}{|c|c|c|c|}
\hline Indicator & $\mathbf{N}$ & $\begin{array}{l}\text { Median } 2000 \\
\text { value (IQR) }\end{array}$ & $\begin{array}{l}\text { Median 2000- } \\
2011 \text { ARC (IQR) }\end{array}$ \\
\hline \multicolumn{4}{|l|}{ Sociodemographics } \\
\hline Adult female literacy rate (\%) & 35 & $54(37$ to 72$)$ & $1.2(0.8$ to 2.7$)$ \\
\hline Female labour participation rate (\%) & 45 & 46 (43 to 49$)$ & $0.1(-0.1$ to 0.3$)$ \\
\hline Fertility rate (births per woman) & 46 & $6(5$ to 6$)$ & $-1.4(-2.1$ to -0.9$)$ \\
\hline Gross domestic product (GDP) per capita (PPP int'l \$) & 45 & 990 (680 to 1900$)$ & $4.2(2.8$ to 5.9$)$ \\
\hline Human development index $(0-1)$ & 39 & $0.38(0.31$ to 0.48$)$ & $1.1(0.7$ to 1.9$)$ \\
\hline Improved sanitation facilities (\%) & 45 & 25 (13 to 45$)$ & $1.6(0.4$ to 2.6$)$ \\
\hline Improved water source (\%) & 45 & 62 (51 to 79$)$ & $1.1(0.2$ to 1.8$)$ \\
\hline Labour force participation rate among women (\%) & 45 & 66 (50 to 76$)$ & $0.3(-0.1$ to 0.6$)$ \\
\hline Urban population prevalence (\%) & 46 & 35 (22 to 44$)$ & $1.3(0.7$ to 1.6$)$ \\
\hline Women with at least some secondary education (\%) & 23 & 16 (10 to 30$)$ & $3.2(2.5$ to 5.2$)$ \\
\hline \multicolumn{4}{|l|}{ Maternal health } \\
\hline Pregnant women receiving prenatal care (\%) & 38 & 77 (64 to 88$)$ & $1.3(0.6$ to 2.7$)$ \\
\hline Adult female mortality rate (rate per 1000 persons) & 46 & 360 (280 to 420$)$ & $-1.2(-1.8$ to -0.6$)$ \\
\hline Maternal mortality ratio (rate per 100000 births) & 45 & 550 (400 to 840$)$ & $-3.7(-4.6$ to -2.0$)$ \\
\hline \multicolumn{4}{|l|}{ Access to health care } \\
\hline Seeking ARI treatment (\%) & 33 & $40(27$ to 55$)$ & $1.7(-0.3$ to 4.9$)$ \\
\hline Births attended by skilled health staff (\%) & 37 & 47 (39 to 60$)$ & $2.0(0.3$ to 3.3$)$ \\
\hline Children with fever receiving antimalarial drugs (\%) & 30 & 53 (32 to 61$)$ & $-4.9(-7.8$ to -0.2$)$ \\
\hline Diarrhoea treatment (\%) & 25 & 39 (28 to 45$)$ & $2.2(-1.4$ to 5.5$)$ \\
\hline Physicians (rate per 100000 persons) & 23 & $5.7(2.9$ to 12.0$)$ & $1.2(-0.6$ to 5.1$)$ \\
\hline \multicolumn{4}{|l|}{ Child survival interventions } \\
\hline Children 1 year old receiving all basic vaccinations (\%) & 26 & $41(29$ to 65$)$ & $2.7(1.1$ to 5.1$)$ \\
\hline Exclusive breastfeeding (\%) & 36 & 25 (14 to 37$)$ & $4.0(-0.2$ to 8.2$)$ \\
\hline Measles immunisation (\%) & 46 & 69 (49 to 76$)$ & $1.3(0.3$ to 2.5$)$ \\
\hline Use of insecticide-treated bed nets (\%) & 30 & 2 (1 to 4$)$ & $29.0(24.0$ to 35.0$)$ \\
\hline Vitamin A supplementation coverage (\%) & 37 & 91 (78 to 96$)$ & $-0.3(-2.0$ to 0.7$)$ \\
\hline \multicolumn{4}{|l|}{ Clinical and health conditions } \\
\hline Adult prevalence of HIV (\%) & 43 & $4(1$ to 8$)$ & $-0.8(-3.6$ to 1.7$)$ \\
\hline Low-birthweight babies (\%) & 30 & 13 (11 to 17$)$ & $-0.3(-3.7$ to 1.0$)$ \\
\hline Malnutrition prevalence (height for age) (\%) & 34 & 40 (34 to 48 ) & $-1.1(-2.4$ to 0.2$)$ \\
\hline Malnutrition prevalence (weight for age) (\%) & 34 & 22 (18 to 27$)$ & $-1.8(-3.3$ to -1.0$)$ \\
\hline Prevalence of wasting (\%) & 34 & 9 (7 to 12$)$ & $-1.9(-5.3$ to 0.5$)$ \\
\hline \multicolumn{4}{|l|}{ Governance and financing } \\
\hline External resources for health (\%) & 45 & $13(4.6$ to 20$)$ & $6.2(-1.1$ to 9.8$)$ \\
\hline Health expenditure (\% of GDP) (\%) & 45 & 5 (4 to 6$)$ & $1.4(0.5$ to 3.2$)$ \\
\hline Health expenditure (\% of government expenditures) (\%) & 45 & $9(7$ to 10$)$ & $2.5(-0.4$ to 3.6$)$ \\
\hline Net bilateral aid flows from DAC donors (US\$ in millions) & 46 & $120(40$ to 260$)$ & $8.7(4.9$ to 15.0$)$ \\
\hline Net ODA received (\% of GNI) (\%) & 46 & $9(4$ to 13$)$ & $-0.9(-5.6$ to 5.3$)$ \\
\hline Net ODA received per capita (US\$) & 46 & 23 (15 to 41$)$ & $7.1(2.4$ to 13.0$)$ \\
\hline Out-of-pocket health expenditure (\%) & 45 & 43 (26 to 58$)$ & $-1.7(-4.0$ to -0.6$)$ \\
\hline Public spending on education (\% of GDP) (\%) & 34 & $4(3$ to 5$)$ & $2.0(0.2$ to 3.8$)$ \\
\hline $\begin{array}{l}\text { Public spending on education (\% of government } \\
\text { expenditure) }(\%)\end{array}$ & 25 & $16(14$ to 19$)$ & $1.6(-0.2$ to 3.0$)$ \\
\hline Safety and Rule of Law (0 to 100) & 46 & 54 (43 to 66$)$ & $-0.0(-0.9$ to 0.4$)$ \\
\hline \multicolumn{4}{|l|}{ Other factors } \\
\hline Households with television (\%) & 24 & $18(6$ to 29$)$ & $6.5(4.0$ to 10.0$)$ \\
\hline Internet users (rate per 100 persons) & 46 & $0.2(0.1$ to 0.5$)$ & $29.0(22.0$ to 38.0$)$ \\
\hline Population coverage of cell phones (\%) & 26 & 37 (17 to 82$)$ & $8.2(1.3$ to 15.0$)$ \\
\hline
\end{tabular}

ARC, annual rate of change; ARI, acute respiratory infection; DAC, Development Assistance Committee; GNI, gross national income;

ODA, Official Development Assistance; PPP int'l \$, purchasing power parity of GDP converted to international dollars.

in fertility rate as the transition enters the final stages such the fertility rates once again come to parallel mortality rates.

Few other studies have explored the association between changes in health, economic and financing factors and ARRs in child mortality. Fotso et $a l^{21}$ studied U5M ARRs from 22 African countries using data from 1988 to 2004. Larger increases in access to clean water and receipt of basic vaccinations (BCG); diphtheria, pertussis, tetanus; measles; and polio) were associated with 


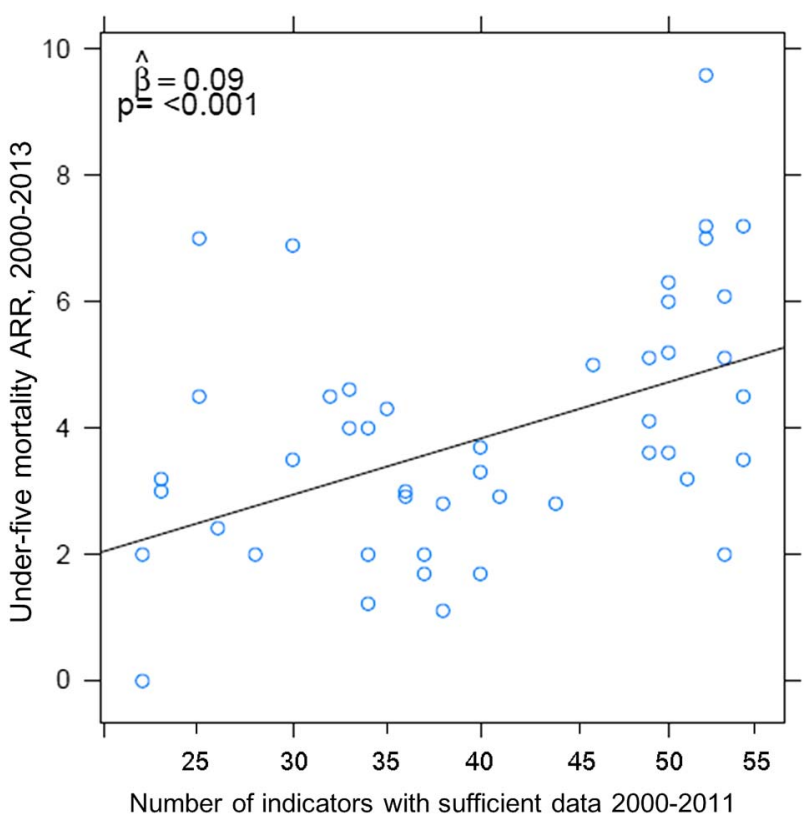

Figure 2 Correlation between under-five mortality ARR and completeness of indicator data for 46 countries in the WHO African Region for the period 2000-2013. The coefficient of 0.09 suggests that for every additional 11 factors reported by a country, there is a corresponding $1 \%$ increase in the ARR.

larger ARRs, while higher increases in urban populations were associated with lower ARRs. Our analyses found increases in access to clean water and urban population to be related to ARR, but these were not statistically significant. Findings from Fotso et $a l^{21}$ are not directly comparable to ours, however, given their earlier time period under study, inclusion of fewer countries and focus on urban areas and no multivariable analyses.

Binkin et $a l^{12}$ studied U5M ARRs from 19 African countries using data primarily from the late 1990 s to mid-2000s and grouping specific interventions into composite indices representing antenatal care, access to delivery services, seeking treatment, immunisations, breastfeeding and nutritional status. Of these, antenatal care, access to delivery services (including a skilled attendant at delivery, delivery in a health facility and/or caesarean section), and improved nutritional status (including reductions in underweight, stunting and/or wasting) were associated with higher ARRs. We did not find these associations in our analysis. And unlike our finding of increased coverage of seeking ARI treatment to be associated with higher ARRs, Binkin et $a l^{12}$ did not find seeking health treatment (including ARI treatment and diarrhoea treatment) to be associated with ARR. Again, however, their analyses differed from ours in terms of time period of study and number of countries included.

Lawn et $a l^{22}$ assessed how annual rates of change in 11 factors representing context (gross national income, general and adolescent fertility rate, female literacy, total health expenditure, government effectiveness, political stability and female HIV prevalence) and coverage (skilled birth attendance, tetanus prevention at birth and diphtheria, pertussis, tetanus vaccine coverage) were associated with neonatal mortality (not U5M) ARR between 2000 and 2010. Of these, only improved coverage of tetanus protection at birth was found to be associated with lower neonatal mortality ARR, a counterintuitive finding. The authors argued that the paradox arose from the fact that the nations investing the most in scaling up tetanus coverage were those with the weakest health systems, high neonatal mortality and lower coverage of interventions. Many of the contextual factors analysed by Lawn et al were found to have small and statistically non-significant associations in our analysis of U5M ARR.

Other ecological studies of country-level factors and under-five or infant mortality rates (not ARRs) have found the following to be associated with lower mortality in Africa: having a skilled attendant at delivery, ${ }^{23}$ exclusive breast feeding, ${ }^{24}$ prevention of mother-to-child transmission of HIV and antiretroviral therapy for children, ${ }^{25}$ diphtheria, pertussis, tetanus or measles vaccination, ${ }^{25}$ use of insecticide treated nets, ${ }^{25} \mathrm{HIV}^{26}{ }^{27}$ health expenditures, ${ }^{26}$ income $^{23}{ }^{27}$ urban population prevalence, ${ }^{28}$ access to clean water, $^{25}{ }^{29}$ female education, $^{23} 2728$ fertility rate $^{28}$ and maternal mortality. ${ }^{29}$ Stunting $^{25}$ and underweight ${ }^{24}$ were associated with increased mortality. While our study found associations between U5M ARRs and changes in only some of these factors, we note that a lack of association between a factor's ARC and mortality ARR does not imply that the intervention or other factor is not associated with reduced mortality. Rather, it means that more rapid scale-up or change in a particular factor does not appear to be associated with a more rapid decline in mortality based on the ARR. During the study period, nearly every African country had declining U5M. A nonsignificant ARC-ARR association could present if such a decline was relatively constant, regardless of whether there was a slow or rapid change in the factor over the corresponding period. It also highlights the need for further research on delivery and subsequent measurement, including assessing quality, of these proven interventions. $^{1930}$

Our findings highlight the role of financing, economy, and the broader health system to more rapidly reduce an already declining, albeit slowly, U5M rate above and beyond the contribution of individual interventions. As the Millennium Development Goals give way to Sustainable Development Goals for 2030, these factors must be addressed to enable further increases in maternal, neonatal and child health interventions. ${ }^{31}$ Model projections suggest that 3.8 million children will still die in 2030 if current $\mathrm{U} 5 \mathrm{M}$ rate ARRs remain steady, and that 2.4 million will die even if ARRs increase substantially. ${ }^{27}$ As U5M rates continue to decline, increasing attention must be paid to neonatal mortality which now accounts for $44 \%$ of all deaths in children under 5 years 
Table 3 Crude and adjusted associations for select factors* and under-five mortality annual rate of reduction, 2000-2013

\begin{tabular}{|c|c|c|c|c|c|c|c|}
\hline & \multirow[b]{2}{*}{$\mathbf{N} \neq$} & \multicolumn{3}{|l|}{ Crude } & \multicolumn{3}{|c|}{ Adjusted† } \\
\hline & & $\bar{\beta}$ & $90 \% \mathrm{Cl}$ & p Value & $\bar{\beta}$ & $90 \% \mathrm{Cl}$ & p Value \\
\hline \multicolumn{8}{|l|}{ Sociodemographics } \\
\hline Adult female literacy rate (\%) & 33 & 0.02 & $(-0.26$ to 0.31$)$ & 0.39 & 0.11 & $(-0.19$ to 0.41$)$ & 0.32 \\
\hline Female labour participation rate (\%) & 42 & -1.07 & $(-2.42$ to 0.29$)$ & 0.17 & -0.32 & $(-1.56$ to 0.92$)$ & 0.36 \\
\hline Fertility rate (births per woman) & 42 & 0.78 & $(0.26$ to 1.31$)$ & 0.02 & 0.54 & (0.07 to 1.02$)$ & 0.07 \\
\hline Human development index $(0-1) \S$ & 35 & 0.12 & (0.04 to 0.20$)$ & 0.02 & 0.09 & (0.01 to 0.17$)$ & 0.07 \\
\hline Improved water source (\%) & 42 & 0.40 & $(-0.05$ to 0.85$)$ & 0.14 & 0.36 & $(-0.07$ to 0.78$)$ & 0.16 \\
\hline Labour force participation rate among women (\%) & 42 & -0.33 & $(-1.19$ to 0.53$)$ & 0.33 & 0.19 & $(-0.57$ to 0.96$)$ & 0.36 \\
\hline Urban population prevalence (\%) & 42 & 0.53 & $(-0.03$ to 1.09$)$ & 0.12 & 0.39 & $(-0.15$ to 0.93$)$ & 0.20 \\
\hline \multicolumn{8}{|l|}{ Maternal Health } \\
\hline Adult female mortality rate (rate per 1000 persons) & 42 & -0.49 & $(-0.83$ to -0.16$)$ & 0.03 & -0.25 & $(-0.61$ to 0.10$)$ & 0.20 \\
\hline Maternal mortality ratio (rate per 100000 births) & 35 & -0.57 & $(-0.80$ to -0.35$)$ & $<0.01$ & -0.47 & $(-0.69$ to -0.24$)$ & $<0.01$ \\
\hline Pregnant women receiving prenatal care (\%) & 35 & 0.09 & $(-0.30,0.48)$ & 0.37 & 0.09 & $(-0.24$ to 0.41$)$ & 0.36 \\
\hline \multicolumn{8}{|l|}{ Access to Health Care } \\
\hline Seeking ARI treatment (\%)ף & 31 & 0.26 & $(0.10$ to 0.42$)$ & 0.02 & 0.22 & (0.09 to 0.35$)$ & 0.01 \\
\hline Births attended by skilled health staff (\%)ף & 34 & 0.21 & $(-0.03$ to 0.45$)$ & 0.14 & 0.18 & $(-0.07$ to 0.43$)$ & 0.19 \\
\hline \multicolumn{8}{|l|}{ Clinical and Health Conditions } \\
\hline Adult prevalence of HIV (\%) & 42 & -0.13 & $(-0.25$ to -0.01$)$ & 0.07 & -0.09 & $(-0.20$ to 0.02$)$ & 0.17 \\
\hline Malnutrition prevalence (height for age) (\%)ף & 32 & 0.11 & $(-0.15$ to 0.38$)$ & 0.31 & 0.15 & $(-0.10$ to 0.40$)$ & 0.24 \\
\hline \multicolumn{8}{|l|}{ Governance and Financing } \\
\hline Health expenditure (\% of GDP) (\%) & 42 & 0.24 & $(0.07$ to 0.40$)$ & 0.03 & 0.26 & (0.11 to 0.41$)$ & 0.01 \\
\hline $\begin{array}{l}\text { Health expenditure } \\
\text { (\% of government expenditures) }(\%)^{\star \star}\end{array}$ & 42 & 0.11 & $(-0.01$ to 0.23$)$ & 0.12 & 0.08 & $(-0.04$ to 0.19$)$ & 0.22 \\
\hline Net ODA received per capita (US\$) & 42 & -0.01 & $(-0.09$ to 0.07$)$ & 0.39 & -0.08 & $(-0.15$ to -0.01$)$ & 0.07 \\
\hline Out-of-pocket health expenditure $(\%)^{\star *}$ & 42 & -0.19 & $(-0.37$ to -0.02$)$ & 0.08 & -0.19 & $(-0.34$ to -0.03$)$ & 0.06 \\
\hline \multicolumn{8}{|l|}{ Other } \\
\hline Households with television (\%) & 23 & 0.29 & $(0.13$ to 0.46$)$ & 0.01 & 0.19 & (0.05 to 0.33$)$ & 0.04 \\
\hline \multicolumn{8}{|c|}{$\begin{array}{l}\text { *Includes all factors for which (1) } \beta>0.20 \text { or } \beta<-0.20 \text {, or (2) } p<0.10 \text {. Factors having both are shown in } b \\
\text { online supplemental table S5). } \\
\text { †All results adjusted for improved water source, health expenditure (\% of GDP), adult HIV prevalence, a } \\
\text { fN=sample size of the adjusted analyses and is }<46 \text { due to missing country data on some of the factors } \\
\S \text { Since the range of the HDI is only from } 0 \text { to } 1, \text { the } \beta \text { represents the change in ARR for each } 0.10 \text { increa } \\
\text { ๆfurther adjusted for receipt of prenatal care. } \\
\text { ** not adjusted for health expenditure (\% of GDP). } \\
\text { ARI, acute respiratory infection; GDP, gross domestic product; ODA, Official Development Assistance. }\end{array}$} \\
\hline
\end{tabular}


of age (34\% in Sub-Saharan African). ${ }^{1} 32$ Facility-based interventions and improving quality care for pregnant women and newborns are needed. ${ }^{32}$ The same financial, economic and broader health system factors that would increase U5M ARRs would also increase reductions in neonatal mortality.

Limitations should be considered when interpreting the findings from this report. First, mortality and indicator data were obtained from secondary sources and some may have suboptimal methods of data collection and model-based estimation, though the World Bank, United Nations Children's Fund, the Interagency Group for Child Mortality Estimation, Demographic and Health Surveys, Multiple Indicator Cluster Surveys and Countdown to 2015 seek to be as authoritative sources as they can. A recent PLoS Medicine Collection highlighted the challenges in obtaining valid coverage data from community-based household surveys. ${ }^{19}$ Second, the study design was an ecological, study. As such, changes in the factors of interest were occurring simultaneously with changes in mortality, and temporality and causality inferences are limited. Ecological studies are prone to bias and associations at the aggregate level (eg, country) may not reflect the cause-effect relationship at the individual or local level. Nevertheless, we felt this design was appropriate given the interest in achieving MDG4, which is monitored at a country level. Third, the time period for calculating the ARCs did not always fully overlap with the time period for calculating mortality ARRs (eg, ARCs for 2000-2011 may have been calculated from data for 2003 and 2010). We attempted to minimise any potential bias by only considering data from factors for which at least a 5-year period of the 11-year time period were available for calculating ARCs. Finally, the small sample size (at most $n=46$ countries) limits the validity of many associations and prevents adjustment for many covariates. We cannot exclude residual confounding and low power to detect certain associations. In spite of these limitations, the unique strengths of our study include our broad identification of factors potentially relevant to child survival, beyond those typically used from Demographic and Health Surveys and Countdown to 2015. We also made statistical efforts to minimise bias or distortion from outliers, without excluding them.

There are numerous interventions, health factors and other determinants of health that influence child mortality rates. However, there are very few studies assessing which of these are associated with higher ARR reflecting more rapid declines in U5M. Policy makers now have evidence that can back decisions to propose increasing access to care for children under age five (extrapolating from our ARI access finding), and increasing health investments, notably towards both child and maternal health.

\footnotetext{
Author affiliations

${ }^{1}$ Vanderbilt Institute for Global Health, Nashville, Tennessee, USA

${ }^{2}$ Department of Medicine, Vanderbilt University School of Medicine, Nashville, Tennessee, USA
}

${ }^{3}$ Department of Biostatistics, Vanderbilt University School of Medicine, Nashville, Tennessee, USA

${ }^{4}$ World Health Organization/Regional Office for Africa, Brazzaville, Congo ${ }^{5}$ Department of Health Policy, Vanderbilt University School of Medicine, Nashville, Tennessee, USA

${ }^{6}$ Pediatrics Vanderbilt University School of Medicine, Nashville, Tennessee, USA

Acknowledgements The authors thank Dr Matshidiso Moeti who inspired the conceptualisation of this study and Jessica Islam for her assistance in reviewing country Demographic and Health Surveys and assisting with data entry.

Contributors AMK helped with the study design, acquisition of data, assisted with data analysis, interpretation of results and drafting the manuscript. He had full access to all of the data in the study and takes responsibility for the integrity of the data and the accuracy of the data analysis. MB assisted with acquisition of data, conducted the analysis and critically revised manuscript. $\mathrm{CAH}$ contributed to the study design, interpretation of results and drafting the manuscript. KM helped with conception and design of the study and critically revising the manuscript. PH helped with conception and design of the study and critically revising the manuscript. BES assisted with data analysis and critically revising the manuscript. MHA assisted with the study design and interpretation and critically revising the manuscript. TK helped with conception and design of the study and critically revising the manuscript. SHV helped with conception and design of the study and drafting the manuscript. All authors have participated sufficiently in the work to take public responsibility for its content.

Funding Funding for this project was provided by the WHO. Support for data management came from the Vanderbilt Institute for Clinical and Translational Research (grant UL1 TR000445 from the National Center for Advancing Translational Sciences at the National Institutes of Health). At the time of the study, Dr. Kipp was a Scholar with the HIV/AIDS, Substance Abuse, and Trauma Training Program (HA-STTP), at the University of California, LoS Angeles; supported through an award from the National Institute on Drug Abuse (R25 DA035692).

Competing interests None declared.

Provenance and peer review Not commissioned; externally peer reviewed.

Data sharing statement Additional data is available at http://biostat.mc. vanderbilt.edu/wiki/Main/WHOUnder5Mortality, or by emailing AMK at aaron. kipp@vanderbilt.edu.

Open Access This is an open access article distributed under the terms of the Creative Commons Attribution IGO License (https://creativecommons.org/ licenses/by-nc/3.0/igo/, which permits use, distribution, and reproduction for non-commercial purposes in any medium, provided the original work is properly cited. In any reproduction of this article there should not be any suggestion that WHO or this article endorse any specific organisation or products. The use of the WHO logo is not permitted. This notice should be preserved along with the article's original URL.

\section{REFERENCES}

1. UNICEF, WHO, World Bank, UNDESA. Levels and Trends in Child Mortality: Report 2014-Estimates Developed by the United Nations Inter-agency Group for Child Mortality Estimation. New York: UNICEF, 2014.

2. UN. United Nations Millenium Declaration. United Nations, 2000.

3. Black RE, Morris SS, Bryce J. Where and why are 10 million children dying every year? Lancet 2003;361:2226-34

4. Jones G, Steketee RW, Black RE, et al. How many child deaths can we prevent this year? Lancet 2003;362:65-71.

5. Bryce J, el Arifeen S, Pariyo G, et al. Reducing child mortality: can public health deliver? Lancet 2003;362:159-64.

6. Victora CG, Wagstaff A, Schellenberg JA, et al. Applying an equity lens to child health and mortality: more of the same is not enough. Lancet 2003;362:233-41.

7. Claeson M, Gillespie D, Mshinda $\mathrm{H}$, et al. Knowledge into action for child survival. Lancet 2003;362:323-7.

8. Countdown to 2015. Tracking Progress in Child Survival: the 2005 Report. Geneva: World Health Organization, 2005. 
9. Bryce J, Terreri N, Victora CG, et al. Countdown to 2015: tracking intervention coverage for child survival. Lancet 2006;368: 1067-76.

10. Countdown to 2015. Building a Future for Women and Children: the 2012 Report. Geneva: World Health Organization, 2012.

11. WHO. Atlas of health statistics of the African region 2012: health situation analysis of the African region. Brazzaville, Republic of Congo: World Health Organization Regional Office for Africa, 2012.

12. Binkin N, Chopra M, Simen-Kapeu A, et al. Do improvements in outreach, clinical, and family and community-based services predict improvements in child survival? An analysis of serial cross-sectional national surveys. BMC Public Health 2011;11:456.

13. The World Bank Data Catalog. http://datacatalog.worldbank.org/

14. Measure DHS country reports. http://dhsprogram.com/ Where-We-Work/Country-List

15. Huber PJ. Robust statistics. New York: Wiley, 1981.

16. Hampel FR, Ronchetti EM, Rousseeuw PJ, et al. Robust statistics : the approach based on influence functions. New York: Wiley, 1986.

17. Venables WN, Ripley BD. Modern applied statistics with $S$.

New York: Springer, 2002.

18. Campbell H, El Arifeen S, Hazir T, et al. Measuring coverage in $\mathrm{MNCH}$ : challenges in monitoring the proportion of young children with pneumonia who receive antibiotic treatment. PLoS Med 2013;10:e1001421.

19. Bryce J, Arnold F, Blanc A, et al. Measuring coverage in $\mathrm{MNCH}$ : new findings, new strategies, and recommendations for action. PLOS Med 2013;10:e1001423.

20. Cutts FT, Izurieta HS, Rhoda DA. Measuring coverage in $\mathrm{MNCH}$ design, implementation, and interpretation challenges associated with tracking vaccination coverage using household surveys. PLOS Med 2013;10:e1001404.

21. Fotso JC, Ezeh AC, Madise NJ, et al. Progress towards the child mortality millennium development goal in urban Sub-Saharan Africa: the dynamics of population growth, immunization, and access to clean water. BMC Public Health 2007;7:218.
22. Lawn JE, Kinney MV, Black RE, et al. Newborn survival: a multi-country analysis of a decade of change. Health Policy Plan 2012;27(Suppl 3):iii6-28.

23. Olafsdottir AE, Reidpath DD, Pokhrel S, et al. Health systems performance in Sub-Saharan Africa: governance, outcome and equity. BMC Public Health 2011;11:237.

24. Abrahams Z, McHiza Z, Steyn NP. Diet and mortality rates in Sub-Saharan Africa: stages in the nutrition transition. BMC Public Health 2011;11:801.

25. Akachi $Y$, Atun R. Effect of investment in malaria control on child mortality in Sub-Saharan Africa in 2002-2008. PLoS ONE 2011;6: e21309.

26. Novignon J, Olakojo SA, Nonvignon J. The effects of public and private health care expenditure on health status in Sub-Saharan Africa: new evidence from panel data analysis. Health Econ Rev 2012;2:22

27. Wang H, Liddell CA, Coates MM, et al. Global, regional, and national levels of neonatal, infant, and under-5 mortality during 1990-2013: a systematic analysis for the Global Burden of Disease Study 2013. Lancet 2014;384:957-79.

28. Chuang YC, Sung PW, Chao HJ, et al. A longitudinal ecological study of the influences of political, economic, and health services characteristics on under-five mortality in less-developed countries. Health Place 2013;23:111-21.

29. Sartorius BKD, Sartorius K. Global infant mortality trends and attributable determinants-an ecological study using data from 192 countries for the period 1990-2011. Popul Health Metrics 2014;12:29.

30. Wazny K, Zipursky A, Black R, et al. Setting research priorities to reduce mortality and morbidity of childhood diarrhoeal disease in the next 15 years. PLoS Med 2013;10:e1001446.

31. Requejo JH, Bhutta ZA. The post-2015 agenda: staying the course in maternal and child survival. Arch Dis Child 2015;100(Suppl 1): S76-81.

32. Wardlaw T, You D, Hug L, et al. UNICEF Report: enormous progress in child survival but greater focus on newborns urgently needed. Reprod Health 2014;11:82. 